\title{
Fluorescence of a Benzothienopyridopyrimidone in Solution and in Lipid Vesicles
}

\author{
Elisabete M. S. Castanheira, ${ }^{1,3}$ Ana M. R. Pinto, ${ }^{1}$ and Maria-João R. P. Queiroz ${ }^{2}$
}

Received November 1, 2005; accepted December 5, 2005

Published online: March 31, 2006

\begin{abstract}
Fluorescence properties of a biologically active benzothienopyridopyrimidone in solution and in lipid vesicles are reported. Assays at different $\mathrm{pH}$ values $(0.5-10)$ allowed the determination of $\mathrm{p} K_{\mathrm{a}}=$ 2.0, showing that this compound may be useful as a $\mathrm{pH}$ indicator for $\mathrm{pH} \leq 4$. In lipid vesicles, benzothienopyridopyrimidone locates in a water-rich environment, indicating that it can be carried in the hydrophilic region of liposomes for drug delivery applications.
\end{abstract}

KEY WORDS: Benzothienopyridopyrimidone; $\mathrm{pH}$ probe; Lipid vesicles.

\section{INTRODUCTION}

Natural tetracyclic heteroaromatic planar compounds, like ellipticine and olivacine (derivatives of carbazoles and pyridines), are known as anti-tumor compounds. Synthetic analogues are being evaluated in order to obtain more active and less toxic compounds, and they are also being studied for other types of biological activity.

A new tetracyclic benzothienopyridopyrimidone $\mathbf{1}$ (Fig. 1) was obtained by us [1], and it was subjected to some biological activity studies. Preliminary studies of antimicrobial activity evidenced selectivity against Bacillus cereus (gram-positive) among representative bacteria and antifungal activity against a Candida albicans species [1]. Recent studies on the antiproliferative activity of compound $\mathbf{1}$ in a panel of human tumor cell lines showed a remarkable cytotoxicity upon UVA irradiation [2].

In previous DNA intercalation studies, compound 1 has shown a low affinity toward the macromolecule [2] and, therefore, we turned our attention to the study of its interaction with lipid membranes. Here we report

\footnotetext{
${ }^{1}$ Departamento de Física, Universidade do Minho, Campus de Gualtar, 4710-057 Braga, Portugal.

${ }^{2}$ Departamento de Química, Universidade do Minho, Campus de Gualtar, 4710-057 Braga, Portugal.

${ }^{3}$ To whom correspondence should be addressed. E-mail: ecoutinho@ fisica.uminho.pt
}

fluorescence studies on benzothienopyridopyrimidone $\mathbf{1}$ in homogeneous solution, varying the solvent and $\mathrm{pH}$, and the fluorescence properties of compound $\mathbf{1}$ when incorporated in lipid vesicles of neutral phospholipids (DPPC and DOPE) and of a cationic lipid (DODAB). The neutral phospholipids DPPC and DOPE are major components of biological membranes, while cationic liposomes based in DODAB have been used as vehicles for DNA transfection and drug delivery [3-5].

\section{EXPERIMENTAL}

\section{Materials and Methods}

All the solutions were prepared using spectroscopic grade solvents and ultrapure water (Milli-Q grade). Buffer solutions of variable $\mathrm{pH}$ were prepared from a mixed solution of $0.2 \mathrm{M}$ boric acid/ $0.05 \mathrm{M}$ citric acid and a $0.1 \mathrm{M}$ solution of sodium phosphate, as described by Perrin and Dempsey [6]. All buffers were adjusted in the $\mathrm{pH}$ range $0.5-10$ by addition of $\mathrm{HCl}$ or $\mathrm{NaOH}$ solution.

1,2-Dipalmitoyl-sn-glycero-3-phosphocholine (DPPC), 1,2-Dioleoyl-sn-glycero-3-phosphoethanola-

ABBREVIATIONS: DPPC, dipalmitoyl phosphatidylcholine; DOPE, dioleoyl phosphatidylethanolamine; DODAB, dioctadecyldimethylammonium bromide. 
<smiles>O=c1c2sc3ccccc3c2nc2ccccn12</smiles>

1

Fig. 1. Structure of the benzothienopyridopyrimidone.

mine (DOPE), both from Sigma, and dioctadecyldimethylammonium bromide (DODAB), from Tokyo Kasei, were used as received (lipid structures are shown below). Lipid/probe films were prepared from stock solutions in chloroform, by evaporation of solvent under a nitrogen stream. Vesicles were formed by hydration of lipids with an aqueous buffer solution (20 mM HEPES and $10 \mathrm{mM}$ $\mathrm{NaCl}$ ), at room temperature for DOPE and at $60^{\circ} \mathrm{C}$ for DODAB and DPPC (above transition temperature of both lipids, $c a .45^{\circ} \mathrm{C}$ [7] and $41^{\circ} \mathrm{C}$ [8], respectively), followed by bath-sonication to obtain optically clear solutions [7,9]. The final lipid concentration was $1 \mathrm{mM}$, with a probe/lipid molar ratio of 1:500. The vesicle solutions were cooled to room temperature and stored for $24 \mathrm{hr}$ prior to measurements.

\section{Spectroscopic Measurements}

Absorption spectra were recorded in a Shimadzu UV3101PC UV-Vis-NIR spectrophotometer. Fluorescence measurements were performed using a Spex Fluorolog 2 spectrofluorimeter. For fluorescence quantum yield determination, the solutions were previously bubbled for $20 \mathrm{~min}$ with ultrapure nitrogen. Fluorescence spectra were corrected for the instrumental response of the system.

The fluorescence quantum yields $\left(\Phi_{\mathrm{s}}\right)$ were determined using the standard method (Eq. 1) [10,11]. 9,10diphenylanthracene in ethanol was used as reference, $\Phi_{\mathrm{r}}=0.95$ [12].

$$
\Phi_{\mathrm{s}}=\left[\left(A_{\mathrm{r}} F_{\mathrm{s}} n_{\mathrm{s}}^{2}\right) /\left(A_{\mathrm{s}} F_{\mathrm{r}} n_{\mathrm{r}}^{2}\right)\right] \Phi_{\mathrm{r}}
$$

where $A$ is the absorbance at the excitation wavelength, $F$ the integrated emission area and $n$ the refraction index of the solvents used. Subscripts refer to the reference (r) or sample (s) compound.

\section{RESULTS AND DISCUSSION}

Absorption spectra of benzothienopyridopyrimidone 1 in different solvents are shown in Fig. 2. It can be observed that the absorption maxima shift to higher energies (blue shift) with the increase of solvent polarity, thus indicating that a $n \rightarrow \pi^{*}$ transition is involved [13]. Despite this, the molar extinction coefficients at absorption maxima $(366-370 \mathrm{~nm})$ are typical of a $\pi \rightarrow \pi^{*}$ transition $(\varepsilon$ values are close to $10^{4} \mathrm{M}^{-1} \mathrm{~cm}^{-1}$ ), suggesting that the two electronic states are nearby in energy, resulting in state-mixing [14].

Figure 3 shows the fluorescence spectra of compound $\mathbf{1}$ in several solvents. A loss of vibrational structure is<smiles>CCCCCCCCCCCCCCCCCCCCCCC(=O)OCC(COP([O])(=O)OCC[N+](C)(C)C)OC(=O)CCCCCCCCC</smiles>

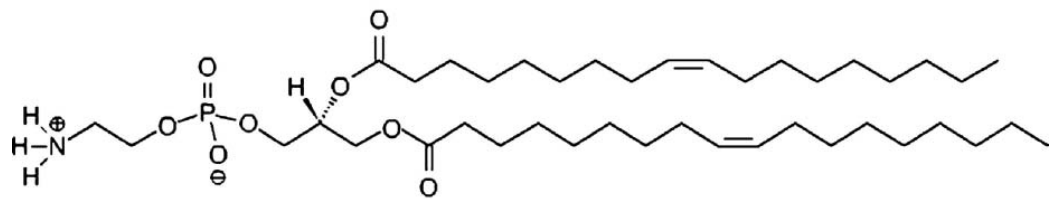

DOPE

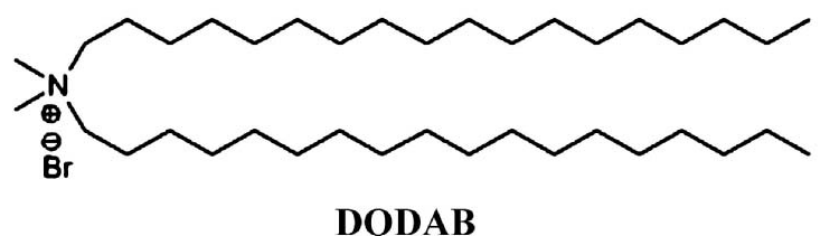




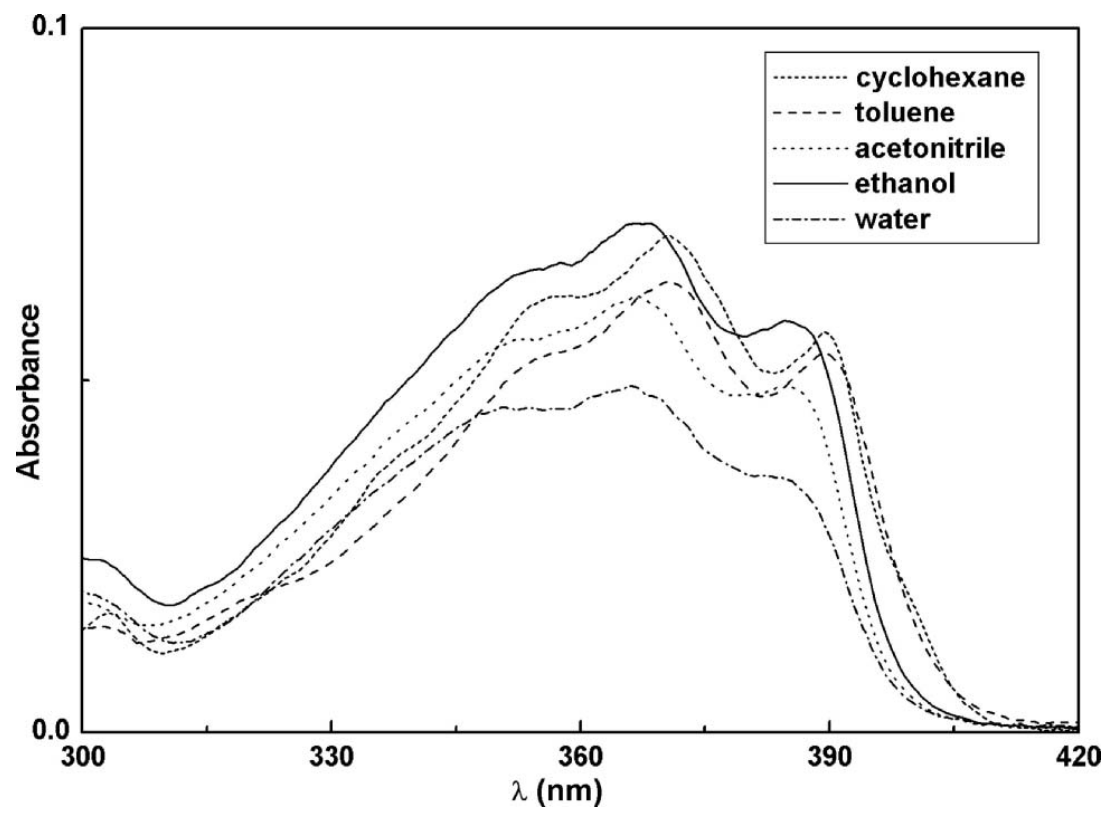

Fig. 2. Absorption spectra of compound $\mathbf{1}\left(4 \times 10^{-6} \mathrm{M}\right)$ in several solvents.

observed in polar organic solvents, which is a common behaviour in several solvatochromic probes $[15,16]$. However, in our case, the emission maximum exhibits only a small solvent dependence. This weak dependence on solvent polarity is also observed in the fluorescence quantum yields (Table I). The presence of the $\mathrm{S}$ atom in the compound structure can promote the intersystem crossing process by enhancement of spin-orbit coupling interaction [14], justifying the low fluorescence quantum yields observed.

The spectrum in water is different in shape and the emission maximum wavelength exhibits a blue shift

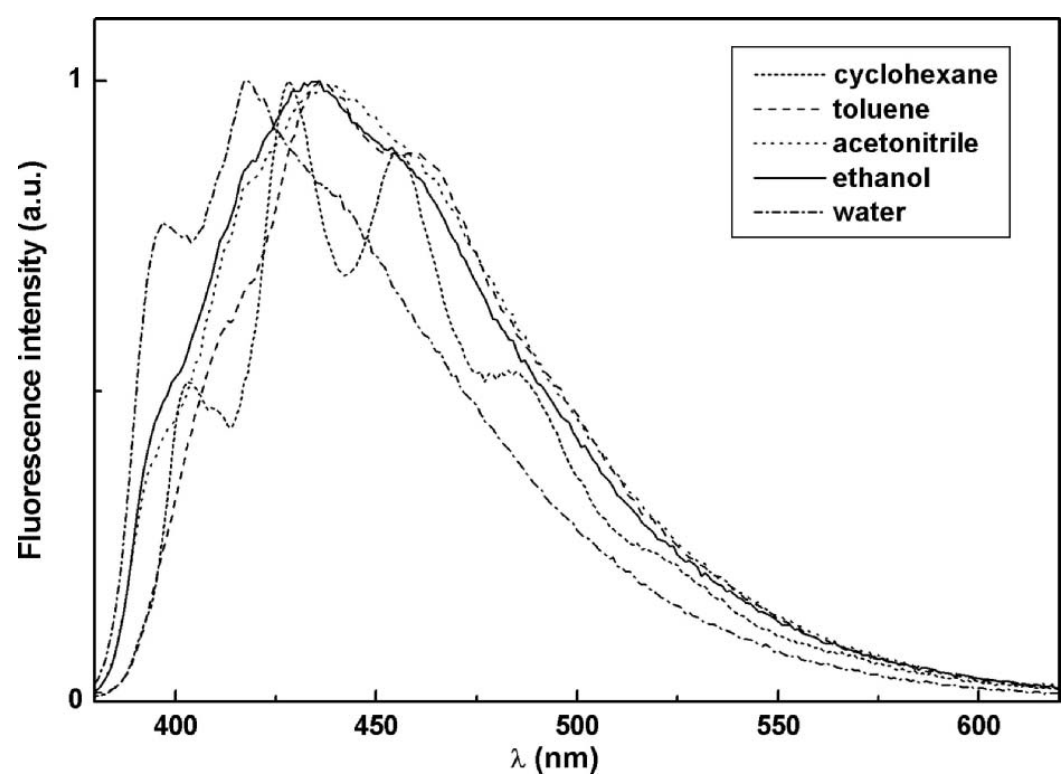

Fig. 3. Normalized fluorescence spectra of benzothienopyridopyrimidone $1\left(4 \times 10^{-6} \mathrm{M}\right)$ in different solvents $\left(\lambda_{\mathrm{exc}}=368 \mathrm{~nm}\right)$. 
Table I. Fluorescence Quantum yields $\left(\Phi_{\mathrm{F}}\right)$ and maximum Absorption and Emission Wavelengths $\left(\lambda_{\text {abs }}\right.$ and $\left.\lambda_{\text {em }}\right)$ for Benzothienopyridopyrimidone in different solvents

\begin{tabular}{lccl}
\hline \multicolumn{1}{c}{ Solvent } & $\lambda_{\text {abs }}(\mathrm{nm})$ & $\lambda_{\mathrm{em}}(\mathrm{nm})$ & $\Phi_{\mathrm{F}}{ }^{\mathrm{a}}$ \\
\hline Cyclohexane & 370 & 428 & 0.12 \\
Toluene & 370 & 437 & 0.18 \\
Dichloromethane & 369 & 436 & 0.13 \\
Dimethylsulfoxide & 368 & 441 & 0.16 \\
Acetonitrile & 367 & 437 & 0.13 \\
Ethanol & 367 & 436 & 0.12 \\
Methanol & 366 & 435 & 0.12 \\
Water & 366 & 418 & 0.14 \\
\hline${ }^{\mathrm{a}}$ Relative to 9,10-diphenylanthracene & in ethanol \\
$\left(\Phi_{\mathrm{r}}=0.95[12]\right)$. &
\end{tabular}

relative to the other solvents. One possible explanation for this behaviour could be the formation of a hydrogen bond between water and compound $\mathbf{1}$ in ground state, which becomes weaker in the excited state. The possibility of compound aggregation in water was ruled out from the measurement of emission at several concentrations $\left(5 \times 10^{-6} \mathrm{M}, 10^{-6} \mathrm{M}\right.$ and $\left.5 \times 10^{-7} \mathrm{M}\right)$, the spectral shape being maintained.

The dependence on $\mathrm{pH}$ of the benzothienopyridopyrimidone 1 emission was also investigated (Fig. 4). The variation of fluorescence intensity at $418 \mathrm{~nm}$ with $\mathrm{pH}$ (inset of Fig. 4) indicates that our compound can be used as a $\mathrm{pH}$ indicator, sensitive to $\mathrm{pH} \leq 4$. The protonation of compound $\mathbf{1}$ at low $\mathrm{pH}$ is responsible for this behaviour. At $\mathrm{pH}=2$ the emission from two different species is clearly observed and spectral changes relative to $\mathrm{pH}=7$ can also be detected in the excitation spectrum (Fig. 5).

The $\mathrm{p} K_{\mathrm{a}}$ value of a compound can be determined using Eq. (2),

$$
\mathrm{pH}=\mathrm{p} K_{\mathrm{a}}+\log \frac{I-I_{\mathrm{A}}}{I_{\mathrm{B}}-I}
$$

where $I$ is the fluorescence intensity at a given wavelength, $I_{\mathrm{A}}$ and $I_{\mathrm{B}}$ are the fluorescence intensities (at the same wavelength) when the compound is only in the acidic form $\left(I_{\mathrm{A}}\right)$ or only in the basic form $\left(I_{\mathrm{B}}\right)$. As usually recommended, it is preferable to determine the ratio $R=I\left(\lambda_{1}\right) / I\left(\lambda_{2}\right)$ of the fluorescence intensities measured at two wavelengths $\left(\lambda_{1}\right.$ and $\left.\lambda_{2}\right)$, applying Eq. (3) as a modified Eq. (2) [15],

$$
\mathrm{pH}=\mathrm{p} K_{\mathrm{a}}+\log \frac{R-R_{\mathrm{A}}}{R_{\mathrm{B}}-R}+\log \frac{I_{\mathrm{A}}\left(\lambda_{2}\right)}{I_{\mathrm{B}}\left(\lambda_{2}\right)}
$$

where $R_{\mathrm{A}}$ and $R_{\mathrm{B}}$ are the $R$ values when only the acidic form or the basic form is present.

In order to determine the $\mathrm{p} K_{\mathrm{a}}$ value of benzothienopyridopyrimidone $\mathbf{1}$, the fluorescence measurements were extended to lower $\mathrm{pH}$ values (Fig. 6).

From Fig. 6, the emission maxima of $418 \mathrm{~nm}$ and $465 \mathrm{~nm}$ were chosen for $\lambda_{1}$ and $\lambda_{2}$. The values of $I_{\mathrm{A}}$ and $R_{\mathrm{A}}$ were obtained from the spectrum at $\mathrm{pH}=0.5$,

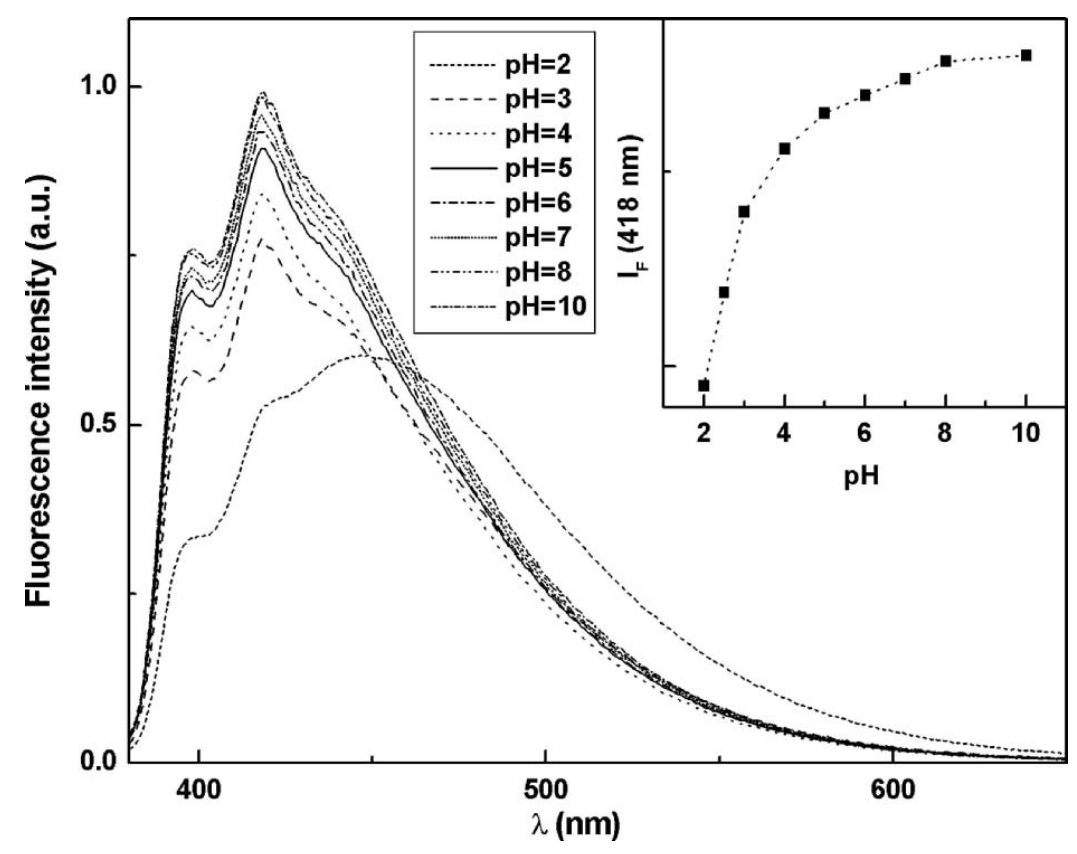

Fig. 4. Fluorescence spectra of benzothienopyridopyrimidone $1\left(10^{-6} \mathrm{M}\right)$ at $\mathrm{pH} 2-10\left(\lambda_{\text {exc }}=\right.$ $368 \mathrm{~nm})$. Inset shows the variation of fluorescence intensity with $\mathrm{pH}(\lambda=418 \mathrm{~nm})$. 


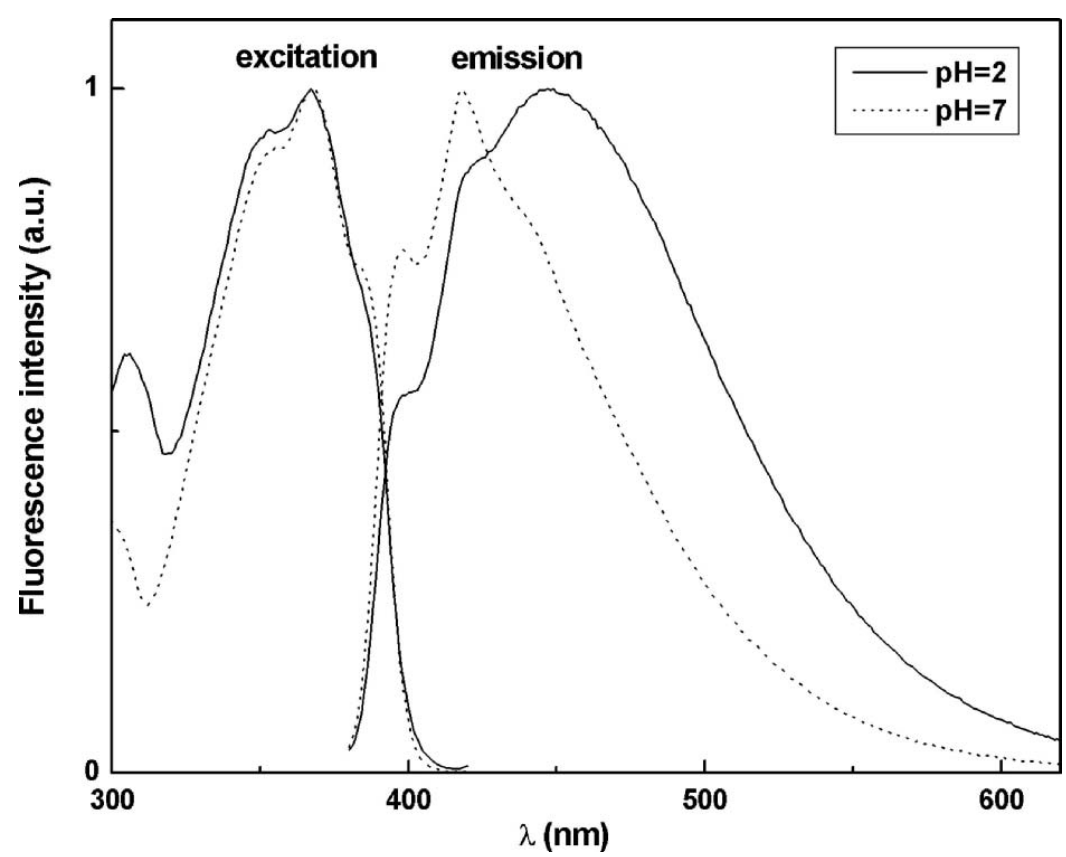

Fig. 5. Normalized excitation $\left(\lambda_{\mathrm{em}}=430 \mathrm{~nm}\right)$ and emission $\left(\lambda_{\mathrm{exc}}=368 \mathrm{~nm}\right)$ spectra of compound $\mathbf{1}$ at $\mathrm{pH}=2$ and $\mathrm{pH}=7$.

while $I_{\mathrm{B}}$ and $R_{\mathrm{B}}$ were taken at $\mathrm{pH}=10$ (Figs. 4 and 6). The fit of Eq. (3) to our experimental data (inset of Fig. 6) allows the determination of $\mathrm{p} K_{\mathrm{a}}=2.0$ for compound $\mathbf{1}$. The usual working range for a $\mathrm{pH}$ indicator is about $2 \mathrm{pH}$ units around the $\mathrm{p} K_{\mathrm{a}}$ value [15], therefore our compound can be considered a $\mathrm{pH}$ probe for $\mathrm{pH} \leq 4$.

In lipid vesicles (Fig. 7), the emission spectra of benzothienopyridopyrimidone $\mathbf{1}$ are very similar to the

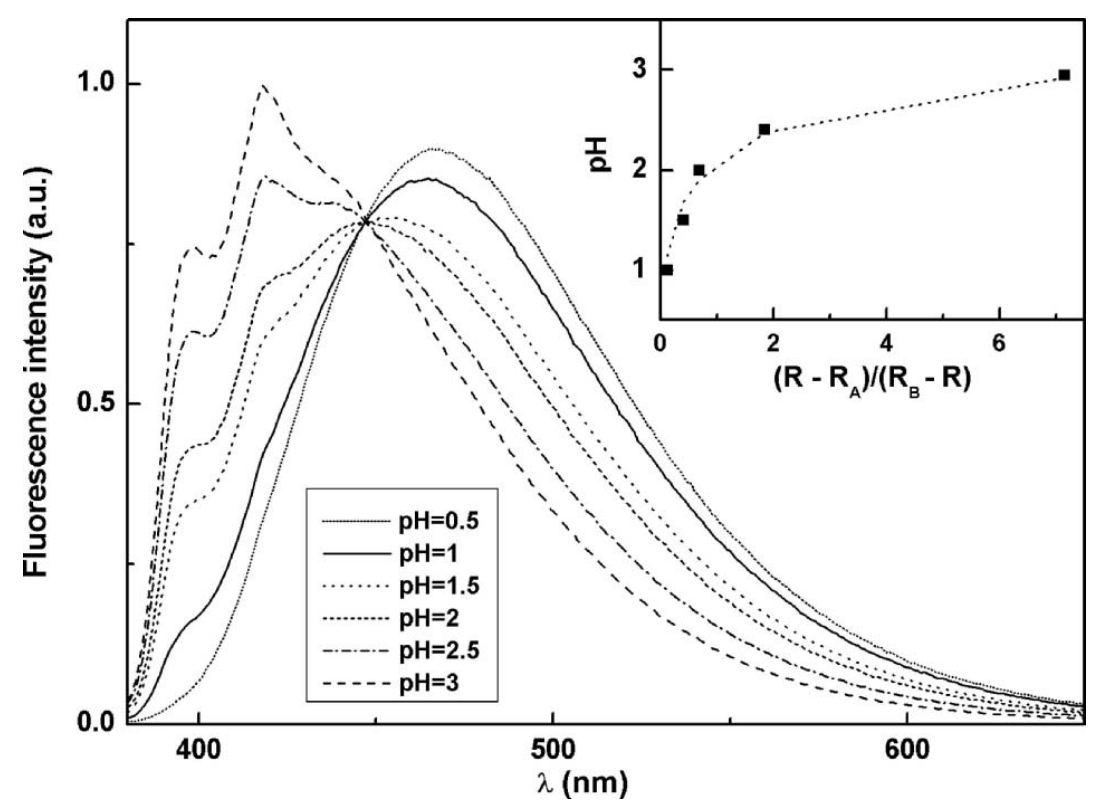

Fig. 6. Fluorescence spectra of benzothienopyridopyrimidone $1\left(10^{-6} \mathrm{M}\right)$ at $\mathrm{pH} 0.5-3\left(\lambda_{\mathrm{exc}}=\right.$ $368 \mathrm{~nm}$ ). Inset shows the fit (dotted line) of Eq. (3) to experimental data. 


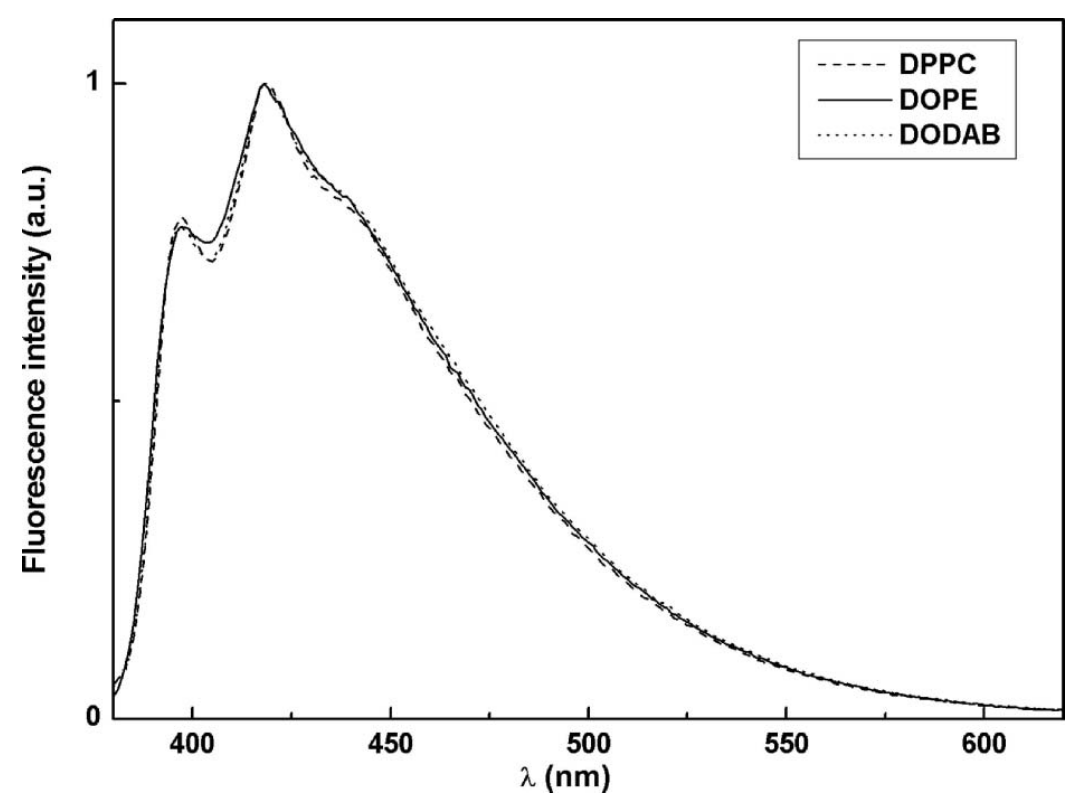

Fig. 7. Normalized fluorescence spectra of compound $1\left(2 \times 10^{-6} \mathrm{M}\right)$ in lipid vesicles of DOPE, DPPC and DODAB $\left(\lambda_{\mathrm{exc}}=368 \mathrm{~nm}\right)$.

emission spectrum in water (Fig. 3) and are also almost insensitive to the lipid type molecule of the vesicles. This behaviour indicates that the compound is in a water-rich environment. To clarify the location of the compound, the vesicle solutions were passed through filters of $0.1 \mu \mathrm{m}$ diameter (Millex). The fluorescence emission of the filtered solutions was negligible, indicating that the compound is in the vesicle aqueous interior or located at the interface, near the polar lipid head groups. These studies may be important for the incorporation of our compound in liposomes for controlled drug release assays.

\section{CONCLUSIONS}

Fluorescence studies on a benzothienopyridopyrimidone show that it may be useful as a $\mathrm{pH}$ indicator for $\mathrm{pH} \leq 4$. Its fluorescence in lipid vesicles shows that the compound prefers a water-rich environment, indicating that it can be incorporated in the hydrophilic region of liposomes for controlled drug release studies. These studies may be important to develop its use as an antimicrobial agent or as an anti-tumoral drug.

\section{ACKNOWLEDGMENTS}

Foundation for the Science and Technology (Portugal) for financial support to Centro de Física and Centro de Química of Univ. Minho.

\section{REFERENCES}

1. M.-J. R. P. Queiroz, A. Begouin, I. C. F. R. Ferreira, G. Kirsch, R. C. Calhelha, S. Barbosa, and L. M. Estevinho (2004). Palladiumcatalysed amination of electron-deficient or relatively electron-rich benzo[ $b]$ thienylbromides - Preliminary studies of antimicrobial activity and SARs. Eur. J. Org. Chem. 3679-3685.

2. G. Viola, A. Salvador, D. Vedaldi, E. Fortunato, S. Disarò, G. Basso, and M.-J. R. P. Queiroz (2006). Induction of apoptosis by photoexcited tetracyclic compounds derivatives of benzo[b]thiophenes and pyridines. J. Photochem. Photobiol. B: Biol. 82, 105-116.

3. D. D. Lasic (1995). In D. D. Lasic and Yechezkel Barenholz (Eds.), Handbook of Nonmedical Applications of Liposomes: From Gene Delivery and Diagnostic to Ecology, CRC Press, New York, Vol. IV, pp. 1-32.

4. D. D. Lasic and D. Ruff (1998). In D. D. Lasic and D. Papahadjoupoulos (Eds.), Medical Applications of Liposomes, Elsevier, Netherlands, pp. 353-394.

5. M. C. Pedroso de Lima, S. Simões, P. Pires, H. Faneca, and N. Düzgünes (2001). Cationic lipid-DNA complexes in gene delivery: from biophysics to biological applications. Adv. Drug Deliv. Rev. 47, 277-294.

6. D. D. Perrin and B. Dempsey (1974). Buffers for $\mathrm{pH}$ and Metal Ion Control, Chapman and Hall, London.

7. E. Feitosa, P. C. A. Barreleiro, and G. Olofsson (2000). Phase transition in dioctadecyldimethylammonium bromide and chloride vesicles prepared by different methods. Chem. Phys. Lipids 105, 201213.

8. B. R. Lentz (1989). Membrane "fluidity" as detected by diphenylhexatriene probes. Chem. Phys. Lipids 50, 171-190.

9. Ira, G. J. Krishnamoorthy (2001). Probing the link between proton transport and water content in lipid membranes. J. Phys. Chem. B 105, 1484-1488.

10. J. N. Demas and G. A. Crosby (1971). The measurement of photoluminescence quantum yields. A review. J. Phys. Chem. 75, 9911024.

11. S. Fery-Forgues and D. Lavabre (1999). Are fluorescence quantum yields so tricky to measure? A demonstration using familiar stationery products. J. Chem. Ed. 76, 1260-1264. 
12. J. V. Morris, M. A. Mahaney, and J. R. Huber (1976). Fluorescence quantum yield determinations. 9,10-Diphenylanthracene as a reference standard in different solvents. J. Phys. Chem. 80, 969-974.

13. C. R. Cantor and P. R. Schimmel (1980). Biophysical Chemistry Part II: Techniques for the study of biological structure and function, W.H. Freeman and Co., New York, Chapter 7.
14. N. J. Turro (1978). Modern Molecular Photochemistry, Benjamin/Cummings Pub., Menlo Park (California), Chapters 5-6.

15. B. Valeur (2001). Molecular Fluorescence-Principles and Applications, Wiley-VCH, Manheim.

16. J. R. Lakowicz (1983). Principles of Fluorescence Spectroscopy, Plenum Press, New York. 